\title{
COMUNIDADE E IMUNIDADE PÓS-COLONIAL: O CAMPO LITERÁRIO E CULTURAL NOS ESPAÇOS DA LÍNGUA PORTUGUESA
}

\author{
Alexandre Montaury Baptista Coutinho \\ (Pontifícia Universidade Católica do \\ Rio de Janeiro)
}

\section{RESUMO}

O texto propõe uma sistematização preliminar do quadro de relações literárias e culturais formadas entre artistas e intelectuais angolanos, brasileiros, moçambicanos e portugueses no âmbito das lutas políticas da modernidade do século XX. Partindo do pressuposto de que essas relações geraram um campo cultural específico que configurou e reconfigurou sentidos de comunidade, pretende-se reconstituir a formação de redes intelectuais que, à margem das instituições oficiais, no plano da escrita literária ou da intervenção cultural, se posicionaram frente a desafios políticos comuns nos últimos sessenta anos.

PALAVRAS-CHAVE: cultura e literatura, modernidade do século XX, comunidade, Portugal, África, Brasil.

\section{RÉSUMÉ}

Le texte propose un cadre systématique préliminaire des relations littéraires et culturelles formées entre les artistes et les intellectuels angolais, brésiliens, mozambicains et portugais dans les luttes politiques de la modernité du XXeme siècle. En supposant que ces relations ont généré un champ culturel spécifique, configuré et reconfiguré par le sens de la communauté, nous avons l'intention de reconstruire la formation de réseaux intellectuels, en dehors des institutions officielles, dans le plan de lécriture littéraire ou d'intervention culturelle, positionné em face de la politique dans les soixante dernières années.

MOTS-CLÉS: Culture et littérature, modernité du XXeme siècle, communauté, Portugal, Afrique, Brésil. 
Os romances preocupam-se com homens vulgares, mais próximos de mim, homens que vivem no meu modesto universo.

Augusto Abelaira (1962, p. 17)

Este texto surge como resultado preliminar das pesquisas que coordeno no Programa de Pós-Graduação em Literatura, Cultura e Contemporaneidade, da Pontifícia Universidade Católica do Rio de Janeiro. Pretendo, com ele, delinear algumas linhas de força que têm se evidenciado no decorrer dessas pesquisas. Mais do que propor a análise de um texto literário ou de um produto cultural, este texto resulta da tentativa de esboçar um quadro inicial que compreenda um conjunto de problemas teóricos identificados no estudo comparativo da produção literária e cultural em língua portuguesa.

O objetivo é o de formular alguns entendimentos, ainda que provisórios, acerca de tópicos relativos às redes de significados culturais e estéticos que, à margem das culturas hegemônicas do ocidente, se abrem de modo transcontinental e transnacional, envolvendo partes da África, parte da Europa e o Brasil, territórios da língua portuguesa em suas variantes.

No ensaio "A literatura brasileira à luz do pós-colonialismo", o crítico Silviano Santiago, ao revisitar a sua trajetória de estudos, aponta para uma espécie metodologia da imunidade que terá induzido os estudos da literatura brasileira a um alheamento em relação às suas interações internacionais, em favor de uma lógica fechada de formação ou de desenvolvimento:

[...] sistemas influentes de pensamento não são autoimunes, embora este ou aquele paradigma, este ou aquele sistema tenha sido apetrechado em favor da própria imunidade. É o caso do sistema literário proposto por Cândido.

Ao cortar ao meio a história colonial brasileira pelo conceito disciplinar de arte literária no Ocidente, o historiador injeta no corpus da produção cultural no Brasil, de 1500 ao presente, a vacina que nomeou "manifestações literárias". Com isso, imuniza o sistema competentemente estetizado, preservando-o do descarrilamento pela África colonial. Libera o estudioso das letras do potencial semântico oferecido pelos quase dois séculos e meio de vida em terras brasileiras do vírus colonial lusitano. (SANTIAGO, 2014)

O sentido de imunidade utilizado aqui pelo crítico vai diretamente ao encontro do horizonte de preocupações deste texto. Entretanto, antes disto, em sintonia com o conceito de campo formulado por Pierre Bourdieu (2000), este texto pretende apenas realçar e evidenciar a forma- 
ção de um campo artístico e intelectual que se caracteriza pela sua heterogeneidade estruturante. Ao invés de investir em um estudo que privilegie uma "retórica oficial da fraternidade" (FINO, 2012), pretende-se identificar lugares específicos de enunciação, que correspondem a diferentes posições políticas assumidas por artistas e intelectuais na cena social da segunda metade do século XX. Do ponto de vista das pesquisas em que atuo, essa percepção é uma premissa a ser trabalhada teoricamente: levanta um campo de problemas que se abre em torno das relações culturais no interior da língua portuguesa, em suas continuidades e descontinuidades, abrindo-se, ao mesmo tempo, para temporalidades heterogêneas e especificidades culturais, para tradições e transições políticas e sociais próprias. Nessa perspectiva, embora seja possível reconhecer aproximações, é preciso não perder de vista as demarcações discursivas e diferenças estruturantes que vitalizam a existência dessas redes culturais.

Do ponto de vista teórico-metodológico, essas pesquisas estão voltadas, em linhas gerais, para a análise de imagens através das quais a cotidianidade foi e tem sido pensada como produção de real no interior desta comunidade linguística em sua complexa diversidade. Neste plano teórico principal se organizam os esforços investidos na articulação de um estudo das teorias associadas às poéticas do comum, às figurações e transfigurações do cotidiano como categoria estética da cultura. É nessa perspectiva que tem sido possível verificar que grande parte das imagens e objetivações literárias que surgem nas culturas de língua portuguesa a interrogar as noções de comum e de cotidiano. Estas imagens foram encenadas, em diferentes momentos, a partir de traços referenciais, ou a partir de recursos documentais, historiográficos ou testemunhais, alegóricos ou mesmo abstratos.

\section{HORIZONTES DE PARTILHA}

No interior dessas comunidades de língua portuguesa, é possível considerar a definição de algumas zonas de partilha, onde significados se dividem e, ao mesmo tempo, se multiplicam e fundam um sentido de pertença, que parece instaurar provisoriamente um espaço comum. No entanto, recorrendo às premissas de Negri e Hardt (2000), verificamos que já não é possível visar a uma noção de comum como formação do mesmo, ou de uma massa monolítica, coesa e homogênea, como arquitetaram os regimes colonialistas europeus dos séculos XIX e XX. Ao contrário, pretende-se entender o comum a partir da constituição de multidões multitudinárias, com especificidades, singularidades e diferenças que, somadas na perspectiva comunitária, possam efetivar o reconhecimento de adversários comuns e inventar um vocabulário de luta comum (bios), conduzida por homens comuns que para Negri:

estão em movimento perpétuo, e formam constelações de singularidades e eventos que impõem contínuas reconfigurações globais no sistema. Esse movimento perpétuo pode 
ser geográfico, mas pode também se referir a modulações de forma e processos de mistura e hibridização. As relações entre "sistema" e "movimentos assistêmicos" não podem ser esmagadas numa lógica de correspondência nessa atopia perpetuamente esmagadora (NEGRI, 2000, p. 79).

O terreno privilegiado das reconfigurações aludidas por Antonio Negri é, certamente, o da "produção da vida", que se materializa como cotidiano, espaço em que a liberdade das formas humanas e a beleza das diferenças se evidenciam. Dispersas em inúmeros romances, as narrativas de pequenos gestos e de movimentos aparentemente irrelevantes, resultam na encenação de diferentes segmentos sociais, expostos ao "centro do acontecer histórico", que é, para Agnes Heller, a vida cotidiana:

A vida cotidiana não está "fora" da história, mas no centro do acontecer histórico: é a verdadeira essência da substância social. Nesse sentido [...], as grandes ações não cotidianas que são contadas nos livros de história partem da vida cotidiana e a ela retornam. Toda grande façanha histórica concreta torna-se particular e histórica precisamente graças a seu posterior efeito na cotidianidade. O que assimila a cotidianidade de sua época assimila também, com isso, o passado da humanidade, embora tal assimilação possa não ser consciente, mas apenas "em-si". (HELLER, 2008, p. 34)

Além de se referirem a práticas simbólicas de uma sociedade específica, às suas "grandes façanhas históricas" e a seus sistemas simbólicos, as encenações do cotidiano também atuam na abertura de brechas na "opressão do presente" (CERTEAU, 1994, p. 31), materializado em ritmo e repetição, criando efeitos de real tensionados entre o ordinário e o insólito.

Passados quarenta anos da Revolução que pôs fim à "imaginação de centro" (Margarida Calafate Ribeiro, 2004, p. 51) que acometeu a cultura portuguesa do século XX e afetou as relações comunitárias, passa a ser possível examinar transformações sociais e culturais que presidiram a constituição de uma mundividência pós-colonial, paradigma decisivo para os estudos atuais. Como lembra o sociólogo Boaventura de Sousa Santos, o pós-colonialismo se configura como:

um conjunto de correntes teóricas e analíticas, com forte implantação nos estudos culturais, mas hoje presentes em todas as ciências sociais, que têm em comum darem primazia teórica e política às relações desiguais entre o Norte e o Sul na explicação ou na compreensão do mundo contemporâneo. Tais relações foram constituídas historicamente pelo colonialismo e o fim do colonialismo enquanto relação política não acarretou o fim do colonialismo enquanto relação social, enquanto mentalidade e forma de sociabilidade autoritária e discriminatória. (SANTOS, 1996, p. 28) 
Podemos dizer que, à margem dos centros hegemônicos do Ocidente, no interior da comunidade cultural da língua portuguesa, a tradição literária do século XX encenou essas relações sociais a partir de clivagens do comum, valor e desafio nacional. A literatura portuguesa antissalazarista, as literaturas africanas anticoloniais e a tradição da literatura modernista brasileira foram pródigas em encenações do cotidiano local, a partir da afirmação de práticas simbólicas próprias, construídas a partir de impasses nacionais. Vale acrescentar que, em advertência às premissas de Benedict Anderson acerca das comunidades imaginadas, Antonio Negri afirmou:

Pode ser verdade que uma nação deva ser entendida como comunidade imaginada - mas devemos reconhecer que a alegação aparece invertida, de modo que a nação passa a ser a única maneira de imaginar uma comunidade. [...] Já sabemos que toda fantasia de comunidade torna-se sobrecodificada como nação e, assim nossa concepção de comunidade fica severamente empobrecida. Da mesma forma que ocorre no contexto dos países dominantes, aqui também a multiplicidade e a singularidade da multidão são negadas na camisa de força da identidade e da homogeneidade de um povo. Mais uma vez, o poder unificador da nação subalterna é uma faca de dois gumes, a um tempo progressista e reacionária (NEGRI, 2000, p. 124).

Neste texto, ir em direção ao nacional não significa regressar aos projetos românticos ou modernistas do nacional, mas sim considerar criticamente os resíduos dos discursos nacionais para buscar e interrogar o comum no interior das dialéticas coloniais. Textos literários dos últimos anos têm procurado encenar "este território embutido de significados culturais e de uma história compartilhada por uma comunidade lingüística" (NEGRI, 2000, p. 122), a partir de emaranhados políticos e culturais e de familiaridades simbólicas aí imbricadas. Para dar apenas alguns poucos exemplos de textos literários recentes que se voltam, direta ou indiretamente, para a interrogação de continuidades e descontinuidades presentes no interior desse universo, podemos citar Desmedida: Luanda, São Paulo, São Francisco e volta: crônicas do Brasil (2006), de Ruy Duarte de Carvalho; Estive em Lisboa e lembrei de você (2009), de Luiz Ruffato; O esplendor de Portugal (1997) e Boa tarde às coisas aqui em baixo (2003), de António Lobo Antunes; Yaka (1984) e A geração da utopia (1992), de Pepetela, e muitos outros. Esses são apenas alguns dos textos onde se encenam criticamente e, portanto, a partir de diferentes enfoques, os desafios pós-coloniais e descoloniais que presidem as práticas cotidianas nesses territórios.

Estes textos, analisados a partir da perspectiva teórica apresentada, permitem a formulação de argumentos mais precisos acerca da articulação de significados do cotidiano no coração da língua portuguesa. As referências aos signos da modernidade e aos conturbados processos nacionais dela derivados produziram efeitos imediatos na cotidianidade de segmentos sociais específicos. Nesse compasso, é possível identificar "per- 
cepções, expressões, entendimentos e impasses revelados pelo curso da expansão geográfica e cultural europeia, e da modernidade civilizacional, ao longo dos séculos" (CARVALHO, 2006, p. 314), cumprindo assim uma travessia pelas experiências e pelas projeções artístico-literárias que essas culturas e lugares fermentaram no plano do imaginário da língua portuguesa.

Esses tópicos apontam, antes de tudo, para um horizonte de partilha das especificidades culturais que marcam os espaços de língua portuguesa e revelam, ao mesmo tempo, uma saturação das lutas tradicionais e modernas em torno da nação. Esse horizonte de partilha, convertido em substância da própria ideia de comunidade, se apoiou, primeiro, na materialidade linguística; depois, nos diferentes legados históricos e culturais que produziram relações múltiplas na órbita dos processos coloniais e das transições que, nos últimos quarenta anos, os sucederam. No âmbito dessas transições, tornou-se recorrente verificar o emprego de um sentido de comunidade que pressupõe uma "mútua pertença" (SÁ in ESPOSITO, 2010, p. IX), ou uma dádiva prévia, que, ao privilegiar semelhanças, negligencia as diferenças estruturantes deste campo cultural.

Com este enfoque preliminar e a partir da análise integrada dos textos de ficção e crítica selecionados, tem sido possível verificar que as imagens literárias através das quais foram pensados e encenados os modos de viver, de fazer, de sentir, de pensar e de crer - em segmentos específicos desses diferentes espaços - delineiam um impasse teórico. Por um lado, ainda presente no pensamento crítico, a afirmação moderna de unidade, de integração e de "comunitarismo luso-afro-brasileiro" reforça heranças culturais do passado colonial e do projeto lusotropicalista (FREYRE, 1940), aderindo a uma conciliação de diferenças em favor de um pertencimento à comunidade lusófona. Por outro lado, é possível identificar, na maior parte da ficção produzida no período, a recorrente afirmação da diferença e a demarcação política e cultural, postas em prática de maneira frontal em textos programáticos, ou numa estratégia de linguagem que interroga a apreensão familiar das experiências da modernidade.

Contudo, não é possível negar a formação de redes operativas no interior desse campo literário e cultural, nos espaços em que recai o presente estudo. Parece necessário situá-las no âmbito das lutas empreendidas por correntes artísticas e intelectuais da modernidade. Com alcance transnacional e compostas por singularidades fortes, essas redes operativas atuaram no reconhecimento de inimigos e adversários comuns - o colonizador na África, o salazarismo em Portugal, a tradição autoritária brasileira - e, finalmente, na resistência às condições políticas que se evidenciavam no cotidiano dos segmentos sociais imediatamente expostos a essas adversidades.

Neste sentido, o estudo tem evidenciado um amplo inventário de dissidências e de rupturas, que inocularam progressivamente, nos discursos da tradição, impurezas que atuam como focos de resistência a um sentido metafísico de comunidade. 
O desenvolvimento deste estudo tem permitido que, além do levantamento analítico e genealógico de discursos do "ser em comum" (NANCY apud ESPOSITO, 2003, p. 9) nos espaços da língua portuguesa, seja reconhecido também o protagonismo de uma estética realista que, em suas diferentes formas de expressão, aparece à superfície dos textos examinados como dispositivo privilegiado de representação das heranças coloniais e das negociações pós-coloniais, tal como se inscrevem na ficção produzida atualmente, nesses diferentes países.

No primeiro segmento da pesquisa, propõe-se uma abordagem que engloba a literatura antissalazarista, o modernismo brasileiro, a ficção anti e pós-colonial africana, que configuram exemplos evidentes e relevantes na formação desses diálogos. Nessa direção, este segmento pretende destacar e ressaltar as formas de cumplicidade estética e política que se materializaram em atuação conjunta, em diversos momentos no período abordado.

À margem de um sentido metafísico de comunidade, artistas e intelectuais constituíram redes operativas e ressignificaram o sentido tradicional e homogeneizante de comunidade, para ativar e pôr em movimento um sistema de relações, referências, citações e apropriações que deram forma a uma zona de partilhas.

A interlocução mantida, por mais de cinquenta anos, entre Jorge Amado e Alves Redol(LOPES, 2012, p. 13), entre José Luandino Vieira, António Jacinto e os jovens escritores reunidos em torno da revista Sul (SALIM, 2005), de Santa Catarina, são apenas alguns tópicos que evidenciam a existência de uma rede de cooperações e de afetos a atuar na circulação de ideias e, ao mesmo tempo, revelando maior ou menor centralidade e alcance de suas políticas de ficção. Escritores como Graciliano Ramos, Guimarães Rosa, Raquel de Queiroz, José Lins do Rego, Manuel Bandeira e Oswald de Andrade, além de outros artistas, como Portinari, Glauber Rocha e muitos outros, críticos e intelectuais brasileiros tiveram grande circulação durante o século XX nesses espaços. Da mesma forma, a geração neorrealista portuguesa e o movimento dos novos intelectuais de Angola assumiram papéis decisivos nessas trocas culturais.

Para evidenciar a heterogeneidade do amplo espectro político que preside os diálogos culturais que, no século XX, abarcaram as culturas em língua portuguesa, enumero algumas ligações que demonstram as diferentes ações postas em prática por escritores e artistas. Começo por referir ao texto "Le grand écrivain Pereira Gomes: um combatant", ${ }_{1}$ de Jorge Amado, publicado em 1950 na França, para informar a morte do escritor português Soeiro Pereira Gomes:

Na ilegalidade, sobre as terras oprimidas de Portugal, morreu recentemente um escritor do povo: Soeiro Pereira Gomes, autor de Esteiros. Sua morte é aquela de um combatente, de um soldado da paz, da liberdade, do socialismo. O 
exemplo que ele nos deixa é aquele de um escritor completamente consagrado à vida de seu povo, à sua luta heroica contra a tirania fascista de Salazar. ${ }^{2}$

A leitura deste trecho revela, de saída, a cumplicidade do escritor brasileiro com aquele a quem considerava "o mais nobre dos escritores de língua portuguesa”, e, ao mesmo tempo, afirma uma ruptura frontal com os princípios e com as práticas do Estado Novo português. A frontalidade com que o escritor brasileiro intervém na imprensa francesa pode explicar "o épico sabor da afronta" a que o escritor moçambicano Mia Couto refere na ocasião do seu "encontro com o irmão brasileiro" em Moçambique:

Nós vivíamos sob um regime de ditadura colonial. As obras de Jorge Amado eram objecto de interdição. Livrarias foram fechadas e editores foram perseguidos por divulgarem essas obras. O encontro com o nosso irmão brasileiro surgia, pois, com épico sabor da afronta e da clandestinidade. A circunstância de partilharmos os mesmos subterrâneos da liberdade também contribuiu para a mística da escrita e do escritor. $\mathrm{O}$ angolano Luandino Vieira, que foi condenado a 14 anos de prisão no Campo de Concentração do Tarrafal, em 1964 fez passar para além das grades uma carta em que pedia o seguinte:

"Enviem o meu manuscrito ao Jorge Amado para ver se ele consegue publicar lá no Brasil...” (COUTO, 2011, p. 65)

Neste contexto, a ideia de uma comunidade fundada a partir de uma "comunhão de experiências históricas" (RIAÚZOVA, 1986) se confunde com uma cooperação ideológica, que se materializa em uma resistência cultural contra o autoritarismo oficial e em uma constante vigilância em relação ao mundo moderno e às ações políticas e sociais relevantes. É importante verificar que, entre os anos 60 e 70, no âmbito da Guerra Fria, resistia-se simultaneamente às guerras anticoloniais na África (19611974), à ditadura militar no Brasil (1964-1984) e à truculência salazarista dos anos 60 em Portugal (ROSAS, 2012). ${ }^{3}$ As culturas de resistência formadas neste cenário são heterogêneas e abarcam uma grande pluralidade de formas de expressão e atuação.

Numa abordagem mais diversa, de matriz cultural, o escritor luso-angolano Ruy Duarte de Carvalho expõe, em Desmedidas - Luanda, São Paulo, São Francisco e volta: crônicas do Brasil (2006), um narrador que, em suas digressões, revela a complexidade dos trânsitos culturais em que vivemos nos espaços da língua portuguesa. Ao reconstituir o ambiente de sua juventude nos anos 60, em suas crônicas do Brasil, recupera as referências brasileiras que então circulavam em Moçâmedes, Angola:

[...] a vastidão e o abismo do tanto que não sei e queria saber sobre o Brasil e sobre as questões e a geografia que terei de encarar... Brasília fez eco no princípio dos anos $60 \mathrm{em}$ Angola também, até lotes de terreno da capital federal em construção eram na altura vendidos por lá. E li, durante a 
puberdade e a adolescência, muita literatura brasileira. Tinha uma livraria do Lobito que fazia importação direta do material brasileiro e distribuía pelo resto da colônia. Meu pai comprava livros desses e O Cruzeiro e a Manchete também. Foi assim que lidei muito cedo com os Capitães da areia e ainda estremeço quando deparo, nos sebos de agora, com as capas que a Livraria José Olympio praticava na altura. Era em Moçâmedes que isto acontecia e ainda hoje me permito tautear trechos inteiros das modinhas de Luiz Gonzaga com que o cinema Eurico anunciava as suas tardes de matinê. [...] Jânio, Jango, Brizola, Carlos Lacerda, Assis Chateaubriand, sei lá, e mesmo um certo David Nasser, que era um jornalista de estilo muito ao gosto de alguns de nós na época, autor também de um samba que fez data, nega do cabelo duro/qual é o pente que te penteia [...] E sabiás nós não tínhamos, mas palmeiras sim, maracujá e fruta-pinha, ${ }^{4}$ e eram nossos, não eram portugueses, os siripipis e os catuituis pré-nacionalistas do Ernesto Lara Filho (CARVALHO, 2006, p. 68).

Nessas crônicas do Brasil, o viajante costura pequenos pormenores a visões de mundo que também passam por uma crítica ao uso da cultura brasileira como instrumento ideológico por parte do colonialismo português em Angola:

[...] haveria de alcançar alguma noção mais precisa de um Brasil que mexe comigo desde que me sei gente. Pode ser que sim e pode ser que não. Mas recolho e atravesso, entretanto, tanta informação e tanta emoção, e vou-me apercebendo de tanta posição, e tão diversa, e tão fundamentada toda, por parte dos próprios brasileiros em relação ao que se me oferece, que o melhor mesmo, de momento e, quem sabe, talvez mesmo definitivamente, é não ceder à tentação de expor-me nos riscos de uma qualquer presunção analítica... (CARVALHO, 2006, p. 162).

Mas depois de 1975 até ficava mal revelar apego ao Brasil, fazia parte do "passado" colonial (ainda hoje custa a lembrar esse papo multilusorracialtropicalista, de matriz brasileira, com que o colonialismo português nos andou a massacrar durante décadas), embora o Brasil dos generais tenha sido o primeiro governo do mundo a reconhecer a Angola independente e o seu governo, que se mantém até hoje no poder, ironias, às vezes duplas e até triplas, que a história tece. [...] E ainda assim... porque a Gabriela foi a primeira novela a ser emitida pela televisão angolana... E continuou-se a ouvir o rei Roberto Carlos e o samba sempre foi nosso também e nunca deixou de haver quem venerasse a voz de Elis Regina [...] e foi quando o Chico Buarque nos veio visitar numa de solidariedade internacionalista, pelo menos foi assim que se disse na altura, e arrancou essa glória que é a mulata de chocalho na canela, da Catumbela. (CARVALHO, 2006, p. 67-68) 


\section{COMUNIDADE}

Para tentar compreender os emaranhados políticos e culturais e as familiaridades simbólicas aí imbricadas, recorro ao estudo de Roberto Esposito, "Comunidade, imunidade e biopolítica", como um esforço de examinar o "curto-circuito intelectual" que define o próprio a partir do comum e vice-versa. Para ele, a comunidade era uma tendência, que poderíamos chamar de metafísica, que nos levava a pensar nela num sentido substancialista e subjetivista:

A comunidade era essa substância que conectava determinados sujeitos entre si, na partilha de uma identidade comum. Deste modo, a comunidade aparecia ligada conceitualmente à figura do "próprio": quer se tratasse de apropriar-se do que é comum ou de comunicar o que é próprio, a comunidade era definida por uma pertença recíproca. Seus membros revelavam ter em comum o seu próprio, ser proprietários do seu comum (ESPOSITO, 2010, p. 14).

A partir da análise de textos como La communauté désoeuvrée de Jean-Luc Nancy (1999), La communauté inavouable de Maurice Blanchot (1984), La comunità che viene de Giorgio Agamben (1993) e Communitas. Origine e destino della comunità, de Roberto Esposito (2010), é possível compreender o que essas concepções de comunidade guardam de comum entre si, para examinar as condições de possibilidade de se pensar em uma comunidade que se organiza juridicamente, através da CPLP (Comunidade dos Países de Língua Portuguesa), e no plano do idioma, a partir do Acordo Ortográfico vigente desde janeiro de 2012, ao reunir culturas em língua portuguesa. No momento em que se torna necessário evidenciar as diferenças estruturantes no interior deste campo cultural, pergunta-se quem e o quê é comum no interior deste campo de forças?

$\mathrm{Na}$ esteira desse raciocínio, Esposito define o paradigma da imunidade em contraste com o significado de communitas, entendido como associação humana baseada na ideia de uma mútua pertença, através da partilha, pelos homens que a compõem, de uma dádiva recíproca a partir da qual se cimentasse a sua concórdia e relação. É como negação ou privação desta relação, ou do cum da communitas, que o conceito de imunidade emerge. E a sua emergência marca, segundo Esposito, o próprio desenvolvimento da política moderna. Nela poder-se-á encontrar o aparecimento de uma associação humana não comunitária, cuja fonte se encontra não na gratuidade de uma dádiva recíproca, mas precisamente na impossibilidade de qualquer relação de gratuitidade; isto é, no estabelecimento de uma relação contratual a partir da qual não havendo nada de gratuito, cada um aceita sacrificar sua liberdade individual originária em função de sua segurança, ou, o que é mesmo, da imunização da sua pessoa e da sua propriedade. Nesta linha de argumentação, Esposito aponta para uma: 
alteração da semântica precedente, no sentido, também literal, de que a comunidade, em vez de referir-se a uma propriedade ou a uma pertença de seus membros, remetia a uma alteridade constitutiva que a diferenciava de si mesma e a excluía de qualquer conotação identitária. Mais que por uma substância, ou uma res, os sujeitos da comunidade, tal como era definida nesses trabalhos, revelavam-se unidos por uma falha que os atravessava e os contaminava reciprocamente (ESPOSITO, 2010, p. 86).

No quadro das questões que pavimentam este projeto, é oportuno retomar as proposições de Boaventura de Sousa Santos, quando se interroga acerca do papel dos portugueses no interior das renegociações culturais. Para ele é necessário identificar:

quem somos nós [os portugueses] neste espaço de língua oficial portuguesa, nas nossas diferenças e cumplicidades integradas num mundo crescentemente globalizado, segundo uma lógica em cujos desenhos temos, quando muito, uma participação subordinada, uma lógica que ou trivializa ou, pelo contrário, dramatiza as nossas diferenças, mas em qualquer caso, bloqueia a construção das cumplicidades. (SANTOS, 1996, p. 46).

\section{ESCRITAS PÓS-COLONIAIS}

Partindo do pressuposto de que há uma escrita que pode ser caracterizada como pós-colonial e que esta mantém relação com as práticas artísticas do realismo, gostaria de concluir este texto afirmando que a literatura pós-colonial está diretamente marcada por dispositivos realistas de representação. Nesse sentido, no âmbito das pesquisas desenvolvidas até o momento, busca-se examinar os modos, os objetos, as tensões e os horizontes que têm materializado a "paixão pelo real", considerada como traço fundamental da produção literária e cultural do século XX, em particular nos espaços da língua portuguesa. Assim, trata-se de analisar quer os problemas de contextualização de soluções realistas, quer a afirmação, implícita ou explícita, da crise do realismo para caracterizar a dicção do real. Está pressuposto nesta análise o aprofundamento da correlatividade entre os procedimentos de escrita e os horizontes político-sociais que pavimentaram as transições pós-coloniais da modernidade do século XX à primeira década do século XXI. Neste sentido, a questão decisiva é a remissão do político e do estético, como se alguma coisa da ordem política fosse pré-figurada na operação estética. Importa identificar, em primeiro lugar, as condições de instauração do "realismo" e da "representação" no quadro do pensamento intelectual dos últimos sessenta anos. Em seguida, é necessário analisar como as possibilidades do "realismo" e da "representação" são experimentadas - e foram-no por diversos modos - para verificar as tematizações dos limites do "realismo" e da "representação". 


\section{CONCLUSÃO}

No momento em que se torna necessário evidenciar as diferenças estruturantes no interior deste campo cultural, pergunta-se quem e o quê é comum no interior deste campo de forças? Na esteira desse raciocínio, Esposito define o paradigma da imunidade em contraste com o significado de communitas, entendido como associação humana baseada na ideia de uma mútua pertença, através da partilha, pelos homens que a compõem, de uma dádiva recíproca a partir da qual se cimentasse a sua concórdia e relação. É como negação ou privação desta relação, ou do cum da communitas, que o conceito de imunidade emerge. E a sua emergência marca, segundo Esposito, o próprio desenvolvimento da política moderna.

A partir desse pressuposto, que remonta às discussões políticas dos séculos XVIII e XIX, talvez seja possível dar maior precisão às relações inscritas no interior dessas comunidades culturais e linguísticas sem negligenciar a diferença como marca estruturante de sua identificação.

\section{REFERÊNCIAS BIBLIOGRÁFICAS}

ABELAIRA. Confissões de um Leitor de Romances. Lisboa: Diário de Lisboa, 1961.

AGAMBEN, Giorgio. A comunidade que vem. Trad. António Guerreiro. Lisboa: Editorial Presença, 1993.

BOURDIEU, Pierre. As regras da Arte. São Paulo: Companhia. das Letras, 2000.

BLANCHOT, Maurice. La comunauté inavouable. Paris: Minuit, 1984.

CARVALHO, Ruy Duarte de. Desmedidas - Luanda, São Paulo, São Francisco e volta: crônicas do Brasil. Lisboa: Cotovia, 2006.

CERTEAU, Michel de. A invenção do cotidiano (Dois volumes) Petrópolis: Editora Vozes. 2003

COUTO, Mia. E se Obama fosse africano? e outras interinvenções. Ensaios São Paulo: Companhia das Letras, 2011.

ESPOSITO, Roberto. Bios: biopolítica e filosofia. Prefácio de Alexandre Franco de Sá. Lisboa: Edições 70, 2010.

. Comunidade, imunidade e biopolítica. Disponível em: http:// hemisphericinstitute.org/hemi/pt/e-misferica-101/esposito. Acesso em 11 de janeiro de 2014.

. Communitas: origene e destino de la communità. Buenos Aires: Amorrorto, 2003.

FINO, Carlos. Portugal-Brasil: separados por uma língua comum ou unidos por uma relação especial?. África 21, outubro de 2012. 
FREYRE, Gilberto. O mundo que o português criou - aspectos das relações sociais do Brasil com Portugal e as colônias portuguesas. Rio de Janeiro: José Olympio, 1940.

LOPES, João Marques. Nos espólios dos neorrealistas portugueses. In: Jorge Amado e o neorrealismo português. Lisboa: Centro de Literaturas e Culturas Lusófonas e Europeias da Faculdade de Letras da Universidade de Lisboa, 2012

HELLER, Agnes. O cotidiano e a história. Trad. de Carlos Nelson Coutinho e Leandro Konder. São Paulo: Paz e Terra. 2008.

MIGUEL, Salim. Cartas d'África e alguma poesia. Rio de Janeiro: Topbooks/Academia Brasileira de Letras, 2005

NANCY, Jean-Luc. La communauté désouvrée. Paris: Christian Burgois, 1999.

NEGRI, Antonio e HARDT, Michael. Império. Rio de Janeiro: Record, 2010.

RIAÚZOVA, Helena. Dez anos de literatura angolana. Luanda: União dos Escritores Angolanos, 1986

RIBEIRO, Margarida Calafate; FERREIRA, Ana Paula (orgs.). Fantasmas e fantasias imperiais no imaginário português contemporâneo. Porto: Campo das Letras, 2003.

. Uma história de regressos: império, guerra colonial e pós-colonialismo. Porto: Afrontamento, 2004.

ROSAS, Fernando. Salazar e o poder: a arte de saber durar. Lisboa: Tinta da China, 2012.

; SIZIFREDO, Cristina. Estado Novo e Universidade: a perseguição aos professores. Lisboa: Tinta da China, 2013.

SANTIAGO, Silviano. A literatura brasileira à luz do pós-colonialismo. Folha de São Paulo, São Paulo, 7 set. 2014. Disponível em http://www1. folha.uol.com.br/ilustrissima/2014/09/1511606-a-literatura-brasileira-a-luz-do-pos-colonialismo.shtml. Acesso em 07/09/2014.

SANTOS, Boaventura de Sousa. A gramática do tempo: para uma nova cultura política. São Paulo: Cortez, 1996.

Recebido para publicação em 27/11/14

Aprovado em 18/01/15 


\section{NOTAS}

1 AMADO, Jorge. Le grand écrivain Pereira Gomes: um combatant. In: Lettres françaises a.10, n. 327 (7 de setembro 1950) apud Jorge Amado e o neorrealismo português. Lisboa: Centro de Literaturas e Culturas Lusófonas e Europeias da Faculdade de Letras da Universidade de Lisboa, 2012, p.15

2 Tradução minha.

3 Ver também ROSAS, Fernando; SIZIFREDO, Cristina. Estado Novo e Universidade: a perseguição aos professores. Lisboa: Tinta da China, 2013.

4 No Brasil, fruta-do-conde (sudeste) ou pinha (nordeste).

5 ESPOSITO, Roberto. Comunidade, imunidade e biopolítica. Disponível em: http:// hemisphericinstitute.org/hemi/pt/e-misferica-101/esposito. Acesso em 11 de janeiro de 2014. 